\title{
Advanced Modeling Strategies for Hydraulic Engineering and River Research
}

\author{
Michael Tritthart (D)
}

Citation: Tritthart, M. Advanced Modeling Strategies for Hydraulic Engineering and River Research. Water 2021, 13, 3261. https:// doi.org/10.3390/w13223261

Received: 15 October 2021 Accepted: 14 November 2021 Published: 17 November 2021

Publisher's Note: MDPI stays neutral with regard to jurisdictional claims in published maps and institutional affiliations.

Copyright: (C) 2021 by the author. Licensee MDPI, Basel, Switzerland. This article is an open access article distributed under the terms and conditions of the Creative Commons Attribution (CC BY) license (https:/ / creativecommons.org/licenses/by/ $4.0 /)$.
Institute of Hydraulic Engineering and River Research (IWA), University of Natural Resources and Life Sciences, Muthgasse 107, 1180 Vienna, Austria; michael.tritthart@boku.ac.at

Our society in general and the work environment in particular are currently undergoing a large-scale digital transformation. On a global scale, the United Nations has embraced this development, being supportive toward the implementation of the Sustainable Development Goals and laid out policy targets in the UNDP Digital Strategy [1]. Further acknowledging this development, governments worldwide have defined regional strategies; as a recent example, the European Commission proposed in September 2021 to establish the 2030 Policy Programme "Path to the Digital Decade" [2]. This policy document also specifically addresses the benefits of digitalization to achieve the objectives of the European Green Deal [3]. In particular, the nexus between digital transformation and the management of water resources is highlighted therein, acknowledging that this development is particularly beneficial for the field of water-related engineering. Advances in computer power have led to the evolvement of computational techniques and numerical methods, providing solutions to issues in hydraulic engineering and river research that were considered intractable in the past.

On the one hand, advanced modeling strategies were developed in the traditional field of numerical hydrodynamics and morphodynamics in order to improve simulation speed and accuracy. This involves 1D, 2D, and 3D Reynolds-Averaged Navier-Stokes (RANS) methods, but also high-resolution techniques such as large eddy simulation (LES) have been employed successfully for ever-larger modeling domains. On the other hand, hydroinformatics techniques targeting decision-making and process optimization in hydraulic engineering have matured in recent years, involving various methods in artificial intelligence, such as machine learning. A third pillar that has gained importance in recent years is the dissemination of model-based results to a broader public audience by real-time virtual and augmented reality.

This Special Issue of Water comprises 10 research articles with contributions from 47 authors that highlight recent advances in hydraulic engineering in an applied context. The papers traverse the entire spectrum of model dimensions, starting from real-time 1D-model applications, addressing advances in 2D hydrodynamic and morphodynamics models, to 3D RANS and LES techniques. They also touch on decision-making processes in river management and show the application of computational fluid dynamics (CFD) techniques in related fields of engineering, such as simulating marine waves and nonNewtonian flows in anaerobic digesters.

The paper by Hu et al. [4] presents a novel prediction-correction solver for the rapid 1D simulation of free-surface flows in dendritic and looped river networks. They show that through the combination of several numerical techniques, a solver for river networks can be developed that only requires the solution of tridiagonal linear equation systems, which outperforms existing hydrodynamic codes on dendritic river networks such as the Three Gorges Reservoir network. Yan et al. [5] show in their feature paper how the control time of pumping stations in a cascade of free-surface channels can be determined using a 1D model, such that the upstream water level remains stable under varying discharge conditions. They found several interrelationships between the control time, upstream discharge, and water 
level that allow for practical optimization, as showcased in the example of the Jiaodong water diversion project.

In the 2D modeling domain, Figuérez et al. [6] present a novel treatment of boundary conditions. A modified law of the wall provides validity for all roughness conditions, the eddy viscosity distribution is calculated from a physically based model, and free-surface stress due to wind shear is considered. It was found that particularly the latter feature improves the accuracy of the model in practical contexts. The article by Siedersleben et al. [7] assesses the quality of 2D morphodynamics simulations by comparing models based on typical cross-section data with ones using high-resolution spatial data. Their results indicate that models can be calibrated successfully on either dataset; however, the uncertain geometry between the cross-sections induces higher transport capacities in cross-sectionbased models, which consequently leads to higher predicted erosion than in models built on high-resolution data. Given the large number of models today based on cross-section geometries only, this effect certainly needs to be considered in practical applications in the future.

The feature article by Shoarinezhad et al. [8] addresses the calibration of morphodynamics models in the 3D simulation domain through an example of a curved channel, thereby considering 3D phenomena such as secondary currents using a RANS approach. The manual calibration of morphodynamics models is a time-consuming task, for various different parameters need to be optimized. The paper, therefore, investigates four automatic calibration strategies and compares the results of the models with measured data. The findings indicate that the parameter sets resulting from the automatic calibration procedures are similar to each other, and the models yield acceptable accuracy of the results. Applying the concepts of this study can, therefore, contribute greatly to reducing user-interaction in morphodynamics model calibration in the future. The paper by Wildt et al. [9] investigates the application of a 3D RANS model in simulating gravity currents in reservoirs by modifying the underlying momentum equation. The results show very good agreement with physical model studies and, thus, indicate the suitability of the model for investigating sediment management in reservoirs through venting procedures. The third feature paper of this Special Issue by Yücesan et al. [10], which was also highlighted as Editor's Choice, employs the LES technique to decipher the hydrodynamic interaction between very large-scale coherent structures and a sediment particle at the onset of particle motion. For larger degrees of exposure of the sediment particle, the lift force showed a bimodal frequency distribution, which was not the case for lower exposure. This indicates that particle entrainment is, in fact, strongly influenced by very large-scale turbulent motions.

Li et al. [11] show in their article how the introduction of advanced methods of computational fluid dynamics can also enhance wave modeling in marine simulators. For this purpose, a particle-based simulation technique was used for the water phase, and a novel stochastic fluctuating wind field was introduced. This effectively allows simulating real, wind-induced wave patterns. The challenge of modeling non-Newtonian flows with CFD tools is presented by Oates et al. [12]. Their paper shows the CFD-based optimization of energy efficiency in an anaerobic digester and a comparison of results with a full-scale laboratory experiment. The findings indicate that considering the non-Newtonian fluid properties in the simulation is indeed highly important for correctly calculating the power demand. While non-Newtonian flows are not typically occurring in traditional settings of hydraulic engineering, this study shows that even challenging fluid properties can be simulated correctly using CFD.

However, the application of advanced modeling techniques in the field of hydraulic engineering and river research, in fact, goes beyond numerical methods for solving challenges of hydrodynamics and morphodynamics. This is substantiated in the article by Zhai et al. [13], who analyzed 12 different river management modes in use in the main rivers of 19 provinces and municipalities in China. In order to facilitate the choice of river management strategies, an intuitionistic fuzzy-based decision-making method was 
introduced and tested. The results show that river management can greatly benefit from making use of such techniques in a practical context.

In summary, this Special Issue highlights the broad application context achievable today by employing advanced modeling strategies in hydraulic engineering, river research, and beyond, essentially covering techniques of numerical simulation and hydroinformatics. With further advances in computer power, it can be expected that computational modeling techniques will attain even improved accuracy and speed and can, thus, provide viable solutions to even more engineering challenges in the near future.

Funding: This research received no external funding.

Acknowledgments: The author appreciates the efforts of the Water editors and publication team at MDPI and the anonymous reviewers for their invaluable comments.

Conflicts of Interest: The author declares no conflict of interest.

\section{References}

1. United Nations Development Programme. UNDP Digital Strategy; United Nations: New York, NY, USA, 2019.

2. European Commission. Proposal for a Decision of the European Parliament and of the Council Establishing the 2030 Policy Programme "Path to the Digital Decade" COM/2021/574 Final; European Commission: Brussels, Belgium, 2021.

3. European Commission. Communication from the Commission to the European Parliament, the European Council, the Council, the European Economic and Social Committee and the Committee of the Regions "The European Green Deal" COM/2019/640 Final; European Commission: Brussels, Belgium, 2019.

4. Hu, D.; Lu, C.; Yao, S.; Yuan, S.; Zhu, Y.; Duan, C.; Liu, Y. A Prediction-Correction Solver for Real-Time Simulation of Free-Surface Flows in River Networks. Water 2019, 11, 2525. [CrossRef]

5. Yan, P.; Zhang, Z.; Lei, X.; Zheng, Y.; Zhu, J.; Wang, H.; Tan, Q. A Simple Method for the Control Time of a Pumping Station to Ensure a Stable Water Level Immediately Upstream of the Pumping Station under a Change of the Discharge in an Open Channel. Water 2021, 13, 355. [CrossRef]

6. Figuérez, J.A.; Galán, Á.; González, J. An Enhanced Treatment of Boundary Conditions for 2D RANS Streamwise Velocity Models in Open Channel Flow. Water 2021, 13, 1001. [CrossRef]

7. Siedersleben, J.; Jocham, S.; Aufleger, M.; Klar, R. Morphodynamic Modelling with Uncertain Geometry Input. Water 2021, 13, 2248. [CrossRef]

8. Shoarinezhad, V.; Wieprecht, S.; Haun, S. Comparison of Local and Global Optimization Methods for Calibration of a 3D Morphodynamic Model of a Curved Channel. Water 2020, 12, 1333. [CrossRef]

9. Wildt, D.; Hauer, C.; Habersack, H.; Tritthart, M. CFD Modelling of Particle-Driven Gravity Currents in Reservoirs. Water 2020, 12, 1403. [CrossRef]

10. Yücesan, S.; Wildt, D.; Gmeiner, P.; Schobesberger, J.; Hauer, C.; Sindelar, C.; Habersack, H.; Tritthart, M. Interaction of Very Large Scale Motion of Coherent Structures with Sediment Particle Exposure. Water 2021, 13, 248. [CrossRef]

11. Li, H.; Ren, H.; Duan, X.; Wang, C. An Improved Meshless Divergence-Free PBF Framework for Ocean Wave Modeling in Marine Simulator. Water 2020, 12, 1873. [CrossRef]

12. Oates, A.; Neuner, T.; Meister, M.; Borman, D.; Camargo-Valero, M.; Sleigh, A.; Fischer, P. Modelling Mechanically Induced Non-Newtonian Flows to Improve the Energy Efficiency of Anaerobic Digesters. Water 2020, 12, 2995. [CrossRef]

13. Zhai, W.; Wang, Z.; Ding, J.; Liu, X. An Intuitionistic Fuzzy Based Decision-Making Method for River Operation Management: Practice from China. Water 2020, 12, 1322. [CrossRef] 